\title{
Economic Analysis of Biodigestion as an Appropriate Waste-to-Energy Technology in the Developing World with Case Study
}

\author{
Adam Dellinger \\ Department of Mechanical, Industrial and Manufacturing Engineering \\ The University of Toledo \\ 2801 W. Bancroft Street, Toledo, Ohio, 43606, United States \\ Tel: 1-419-530-8210Ｅ-mail: adam.dellinger@rockets.utoledo.edu \\ Matthew Franchetti (Corresponding author) \\ Department of Mechanical, Industrial and Manufacturing Engineering \\ The University of Toledo \\ 2801 W. Bancroft Street, Toledo, Ohio, 43606, United States
}

Tel: 1-419-530-8051_E-mail: matthew.franchetti@utoledo.edu

\begin{abstract}
Alexander Spivak
Department of Mechanical, Industrial and Manufacturing Engineering

The University of Toledo

2801 W. Bancroft Street, Toledo, Ohio, 43606, United States

Tel: 1-419-530-8210Ｅ-mail: alex.spivak@rockets.utoledo.edu
\end{abstract}

Received: August 1, 2013 Accepted: August 14, 2013

doi:10.5296/emsd.v2i2.4070 URL: http://dx.doi.org/10.5296/emsd.v2i2.4070

\begin{abstract}
The study explores the economic benefits of biodigestion systems as a waste-to-energy conversion technology on individual farms in the developing world. The design components are discussed, including an analysis of the various social, economic and technical factors that
\end{abstract}


influence the system. Finally, these factors are applied to two systems currently in use in different areas of rural Costa Rica. This study concludes that biodigestion can be an attractive economic option as a waste-to-energy technology in the developing world and will result in a positive NPV up to $\$ 4,800$ for an average rural farm over the life of the system.

Keywords: Anaerobic digestion; waste-to-energy conversion; biodigestion; rural sustainability; methane production; developing world

\section{Introduction}

Prior to the turn of the 20th century, high income countries have made efforts to assist low income countries in their development for both altruistic and self-promoting reasons (Archibugia and Coco, 2004). This assistance has come in many forms, including direct aid and the encouragement of investment. However, one of the most effective means of development is the spread of effective technologies, which includes machines and processes to ideas and organizations (Archibugia and Coco, 2004). Today there is a large effort on the part of academia and the nonprofit sector to develop appropriate technologies for the developing world to improve economic, health, and other quality of life metrics (Bell and Pavitt, 1997). At present, developing countries today face a large range of problems, from economic stagnation to energy rationing and environmental degradation as a result of harmful human practices. However, many of the aforementioned aid techniques have failed to produce positive results and may have inadvertently made situations worse (Archibugia and Coco, 2004). Thus, it is important for innovators in the "first world" to work with stakeholders in the "third world" to ensure that solutions are not only technically feasible, but economically, socially and environmentally sustainable (Lull, 2001).

One technology that holds much promise for mitigating not only economic malaise but also energy difficulties and environmental damage in the developing world is anaerobic digestion (AD). AD, classified within the biochemical conversion processes, is a robust process and is widely applied as a series of chemical processes in which organic waste is converted into energy in the form of biogas, which consists mostly of methane but also contains significant carbon dioxide (Appels et al., 2011). The biogas can be used for cooking, heating or electricity generation, while the effluent waste from the process can be used as a crop fertilizer. AD can be employed on a large range of scales, from giant industrial wastewater plants to small low-tech operations, and although it most commonly utilizes livestock or human waste as feedstock, it could theoretically convert millions of tons of food and plant waste generated annually into energy (Budzianowski, W.M., 2012). Thus on a very large scale, AD could potentially help to reduce the effects of greenhouse gases while providing a source of energy and/or economic activity.

Several recent studies have been conducted to research new organic waste to energy technologies (Han et al., 2005; Ke et al., 2005; Mohareb et al., 2008; Muhle et al., 2010; Pimenteira et al., 2004). These studies have focused on organic wastes, but not specifically food waste. These studies primarily focus on the chemical processes and 'proof of concept' analyses, but do not fully explore the neither techno-economic nor environmental impacts of utilizing these technologies related specifically to food waste. This study aims at filling this 
knowledge gap by analyzing and evaluating the economic benefits of utilizing anaerobic digestion on individual farms in rural areas in the form of biodigestion systems. This research also is novel versus previous studies in that it focuses on small farms (10-25 animals) in developing countries. There also exists a body of research dedicated to the technical aspects of simple biodigestion systems for the developing world (Rodriguez and Preston), but they often lack an aspect of economic feasibility analysis. Most current studies in this field, however, are based in developed countries (Budzianowski, 2012), large farms (Demirel and Scherer, 2008; Kaparaju and Rintala, 2005), and focus on the environmental impacts, rather than economic considerations (Muhle, 2010).

In the developing world, biodigestion systems produce biogas for cooking from animal or human waste. The appeal of these systems in rural areas of the developing world is the low financial and educational capital required to understand, construct and maintain them (Archibugia and Coco, 2004). Environmental benefits, though discussed, are not emphasized here since they are difficult to quantify and sensitive to local conditions. In addition, it is unlikely that in an age of global industrial activity, the curbing of greenhouse gases will prove to be a compelling incentive or even a worthwhile endeavor on these smallto medium-size farms. This information could be useful to aid agencies looking to promote sustainable and successful projects in rural areas of developing nations or researchers searching to develop complimentary technologies or processes that could further enhance yield and thus maximize the economic and environmental benefits of AD (Weiske, 2006).

The concept of the biodigestion system is introduced with a brief explanation of how each component of the process works and the various considerations that must be taken into account when designing a system. What follows is the full discussion of the various factors that influence the economic costs and benefits of an individual farmer constructing a biodigestion system. Finally, a brief case study takes those factors and applies them to two different systems that were constructed in a rural area of the Central American nation of Costa Rica.

\section{Materials and Methods}

\subsection{Biodigestion System Design and Components}

A biodigestion system converts organic waste, such as animal manure or plant wastes, to energy. The chemical processes that make this conversion possible are known as anaerobic digestion $(\mathrm{AD})$. This section will explore the multiple components and processes necessary to operate biodigeston systems.

$\mathrm{AD}$ is a series of four processes that eventually convert lipids, proteins and carbohydrates into a mixture of methane gas and carbon dioxide known as biogas. The anaerobic digestion processes occur in the reactor, which can be any enclosure that restricts the entry of oxygen. The reactor can be any size or shape, and involve any number of additional complex processes that enhance biogas production. However, the systems that are the focus of this paper are of the lowest complexity and cost, ideal for rural farmers in the developing world that do not have access to the capital, credit, or quantity of feedstock to make large or 
expensive systems feasible.

The anaerobic digestion that occurs in the biodigestion systems referred to in this paper is one-stage as opposed to two-stage, and is mesophilic (that is, occurring at temperatures between $30-38^{\circ} \mathrm{C}$ ) rather than thermophilic (above $49^{\circ} \mathrm{C}$ ) since the process temperature is typically the ambient air temperature.

The elements of the typical rural biodigestion system are the feedstock, feedstock collection and delivery system, filter, reactor (or tank), effluent management, gas pressure relief valve, gas delivery system, gas storage, and cooker. In most rural settings the building of a small structure around and above the tank or reactor is advisable to protect it both from the sun and from animals.

It must be mentioned that there are several different designs for biodigestion systems, particularly the reactor. Different reactor designs may require various solutions to the components listed here, but all basic systems will have to contain certain elements or processes. The main components of a biodigestion system are elaborated upon below.

Feedstock. A very important element of the biodigestion system is the waste that is being put into it. The quantity and carbon-to-nitrogen $(\mathrm{C} / \mathrm{N})$ ratio of the feedstock, which are strongly correlated with the liveweight and class of animals (i.e., pigs, cows) as well as type and quantity of feed given to them, affect the total gas production of the system and must be taken into account when deciding upon a proper size for the digester. For example, pig waste has an almost ideal $\mathrm{C} / \mathrm{N}$ ratio whereas cow waste does not and may require the addition of plant waste to optimize biogas yield.

Feedstock collection and delivery system. The method of collecting the waste is quite important, especially on farms where labor is a major cost factor; animal enclosures can be designed in order to make waste cleanup and collection an easy task, but where animal enclosures have already been constructed the additional effort necessary to collect the waste must be considered.

Once the waste has been collected, either by a person or via an automatic gravity-fed system, it must be directed into the reactor. For health and safety reasons, it is preferable that the system be designed in such a way that the waste enters the digester with as little human contact as possible.

Feedstock filter. In order for the reactor to work properly, solids must be kept out of the liquid/manure mix that enters it; otherwise, the solids can gather at the top of the mixture and prevent gases from escaping. Thus, some sort of filtering device, such as a sieve, must keep undigested solids from entering into the reactor. This must occur at some point between waste collection and direction into the reactor. It will likely be necessary to periodically clear out the filtered solids as they may otherwise block the system, so this must be taken into consideration during design.

Tank/reactor. The most important aspect of the biodigestion system, the reactor or tank, is the vessel into which the waste enters and out of which the biogas and effluent material exits. 


\section{Macrothink}

The most important qualification of a reactor is that it be airtight, such that no oxygen can enter and disrupt the anaerobic digestion process. It is also very important that the reactor be as durable as possible. An individual contemplating the construction of a biodigestion system can balance the need for a more durable, and thus more expensive reactor by constructing a protective structure, discussed below.

The type of reactor to construct is perhaps the most important decision in the system design, since it has significant bearing on the amount and qualifications of labor used, the initial material cost, and expected life of the system. These ramifications are further discussed in the Section 3.

Figure 1 displays a schematic of a common reactor design. As illustrated, the lowest point of the effluent exit point must be lower than the same point on the influent entry point, as it determines the level of the water/manure mixture inside the reactor; a higher proportion of liquid volume to total reactor volume has been shown to increase yield (Preston and Rodriguez, 2012). Over time, the effluent may periodically clog which will raise the water level in the influent pipe, signaling to the operator that the effluent pipe must be cleared.

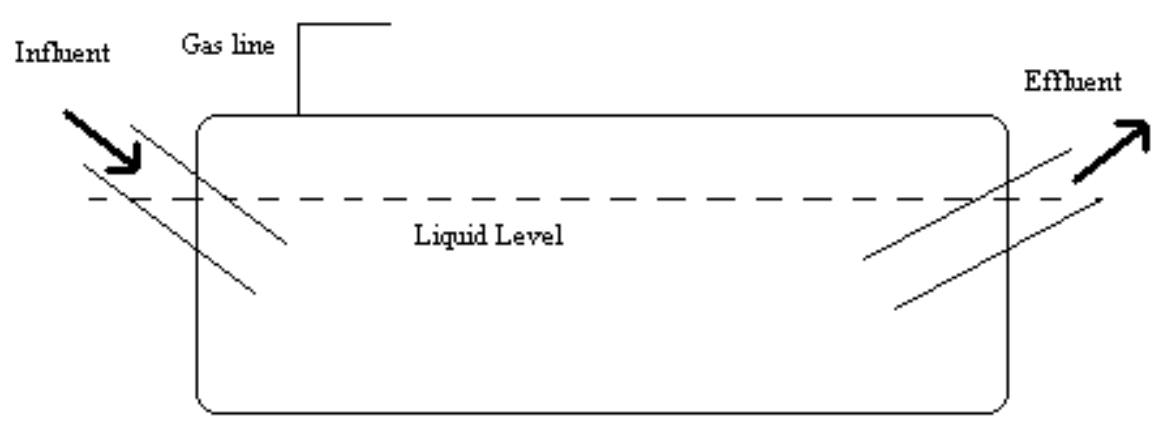

Figure 1. Schematic of Typical Reactor Design

Effluent management. Since the water/manure mixture level inside the reactor stays constant, as new material enters older material exits through the opposite end. This effluent liquid, having been digested by the microorganisms inside the reactor, no longer contains the volatile compounds that it did upon entering. However, it can be used as an effective fertilizer. Thus, any farm can use this material to a beneficial end, whether it is enriching crops that are grown elsewhere or growing crops to feed livestock. If the farmer is uncomfortable with using the effluent material directly on crops, it can be used on other plants (such as duckweed or water lilies) which, once grown, can then be composted. In any case, the management of the effluent liquid from the reactor should be planned prior to design to maximize this additional benefit of biodigestion.

Gas Pressure Relief Valve. As will be discussed in the next section, calculating the estimated supply of gas given the live weight on a farm can be difficult, so not all of the gas produced may be used. Eventually the pressure in the system will have to be relieved; in order to do 


\section{Macrothink}

this without damaging the system, a pressure relief valve in the form of a plastic bottle partially filled with water and attached to the gas line is a necessity. This can be designed depending on the availability of materials in order to reduce initial material cost, and the amount of liquid above the entry point of the gas line determines the maximum tolerable pressure for the system. The pressure relief valve from one of the case study biodigestion systems is shown in Figure 2.

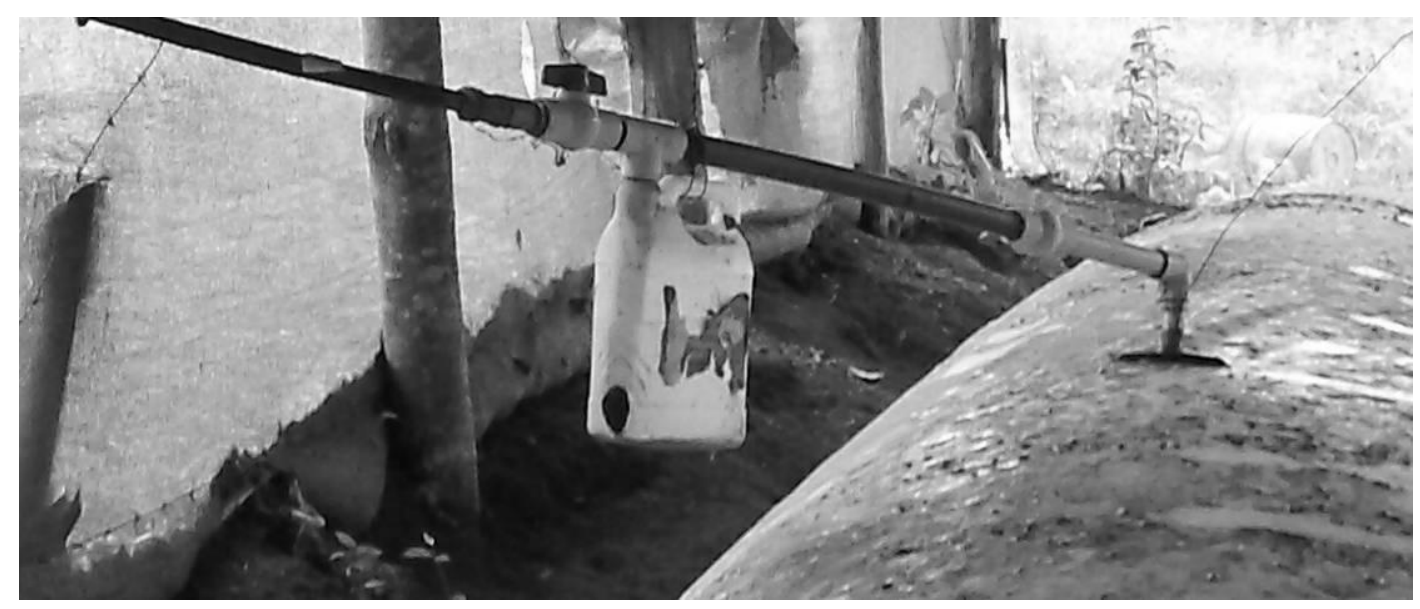

Figure 2. Gas Pressure Relief Valve for Biodigestion System A

Gas Delivery System. Since biogas naturally rises, it is essential that the point of gas production be at the same level as, or ideally, below the point where it will be used. If this is not possible, it may make transporting the gas difficult. It is also important that there be no significant dips in the gas line, otherwise condensation can gather in the dips and block the flow of gas. The presence of trees or fencing to which the gas line can be attached can make installation of the line a simpler process.

Gas Storage. This is not a necessary component of the biodigestion system, but it allows greater control of the produced gas. If desired, a plastic bag can be placed near the cooking location and a hanging weight can be used to increase pressure while cooking and decrease pressure overnight in order to fill the bag. This is an attractive option when the reactor is located far from the cooking location because it essentially allows for greater storage capacity in the event of a maintenance issue with the reactor or gas line.

Cooker. It will be necessary to have a cooker, preferably made of cast metal, which can attach to the gas line via fittings that vary the amount of gas being used to cook. Typically these are lit with matches. 


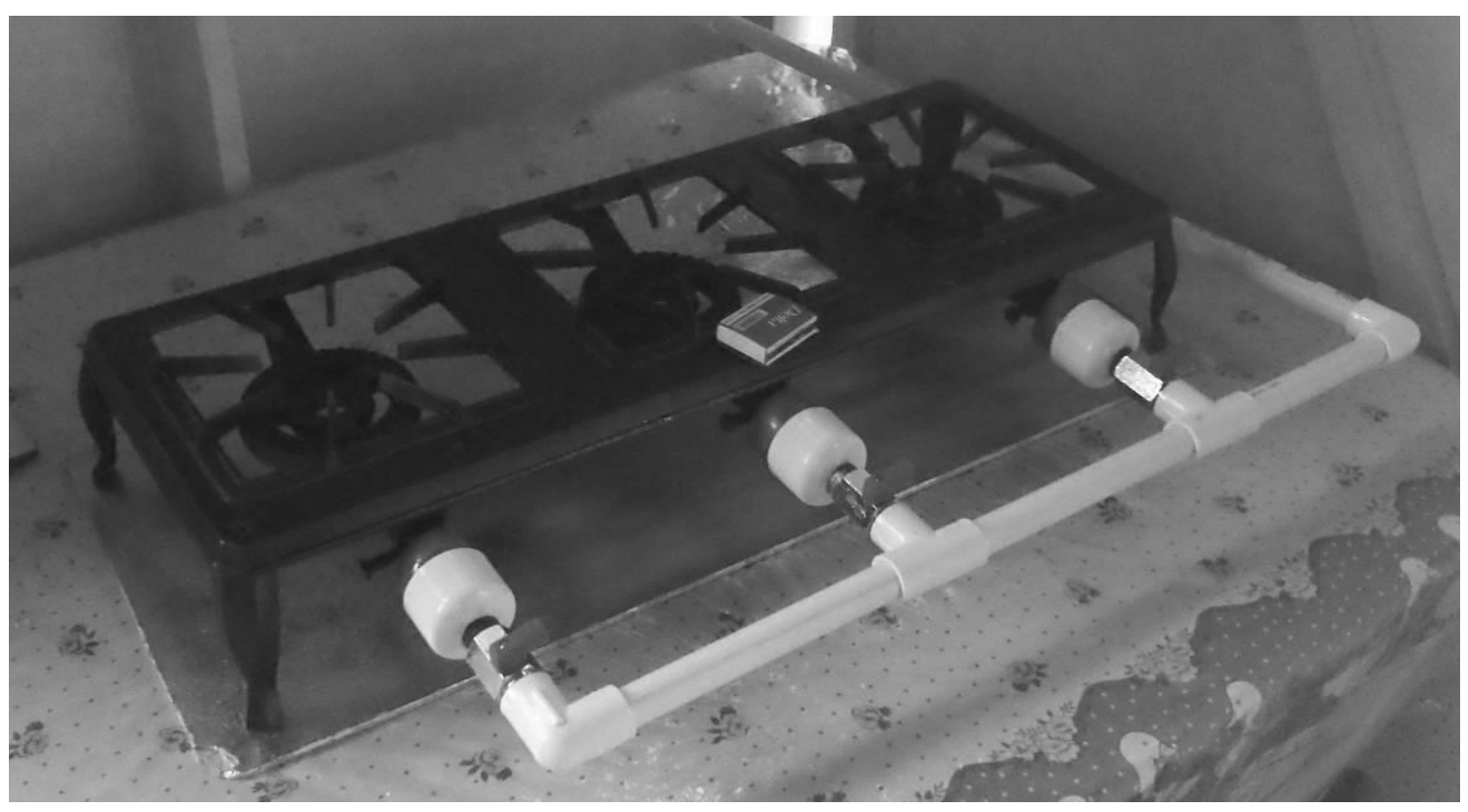

Figure 3. Cast Metal Cooker Necessary to Utilize Biogas as Fuel

Protective Structure. The hot, direct sun of tropical nations and the presence of livestock, domestic animals and birds often necessitate the construction of a structure to protect the reactor, especially if it is made of plastic. The decision to construct this structure will depend on the relative need and the availability of materials such as scrap tin for the roof and wood. Animals can be kept out with various materials depending on availability. If a farmer must purchase all of the materials necessary to construct the protective structure it may affect the economic feasibility of the entire project.

\section{Theory and Calculations}

\subsection{Factors Influencing Economic Benefit of Biodigestion Systems}

As in many personal and business decisions, the economic benefit of a new project is a critical and effective incentive. It is for this reason that this paper focuses on the economic aspects of installing and operating a biodigestion system. Equation 1 was used to calculate the Net Present Value (NPV) for each biodigestion system that was analyzed.

$$
N P V(i, N)=\sum_{t=0}^{N} \frac{R_{t}}{(1+t)^{t}}
$$

where $\mathrm{t}$ is the time of the cash flow; $\mathrm{i}$ is the discount (or interest rate), and $\mathrm{R}$ is the net cash flow. For this study, the projected life of each system (in years) was used for $\mathrm{t}$; the end of year cash cumulative cash flow was used for R; and an interest rate of $16 \%$ was selected for i (World Bank, 2013). This interest was chosen as it is the current lending rate for Costa Rica, though it can vary in different circumstances. As previously mentioned in the introduction, the cost benefit of having a biodigestion system is the production of biogas, which can be used for cooking or electricity generation (in large quantities). However, before embarking on such a project, whether it is an individual farmer with assistance from a neighbor or an aid agency looking to enhance rural development, it is important to consider all of the factors that 
influence the costs and economic benefits of having a biodigestion system on a waste-producing farm.

As with any capital project, there will be a large initial cost of both material and labor that is slowly reimbursed by either a cost savings or increased profit. Over time, the project begins to result in a net profit for the investor. For this analysis, the factors that influence the initial and annual costs of biodigestion projects are listed in roughly chronological order from the beginning of the project to the end.

\subsection{Basic Resources}

The following factors are very important to many cost and profit aspects of the biodigestion system and should be carefully considered while making project decisions, including whether or not to pursue the project in the first place.

Waste Source. It is important to consider how many and what kind of animals are on the farm. If there is not a necessary amount of animals, it may not be worthwhile to engage in the project since their waste will not produce enough gas to support the needs of a family. Using calculations from the FAO Biogas Manual, about five adult pigs (500kg liveweight) should produce enough waste to support the cooking needs of one family (Rodriguez and Preston). Beyond that, the number of animals should influence the chosen size of the reactor as there is an ideal retention time for waste to remain inside the reactor. Pig waste is an ideal feedstock for biodigestion but cow and other animal waste can be mixed with plant waste to create the ideal $\mathrm{C} / \mathrm{N}$ at the cost of more labor.

For larger farms, the additional cost of constructing and maintaining a larger reactor must be balanced with the expected economic benefit of the biogas produced by the larger number of animals.

The type of feed given to the animals also influences the biogas production per $\mathrm{kg}$ of waste, and certain types of feed may result in higher amounts of solids being filtered by the feedstock filter.

Labor Source. Who will construct and maintain the system? Is the farmer performing the labor himself or does he/she pay a laborer to complete other tasks on the property? What is the cost of labor in the area? Even if the farmer performs his/her own labor, time spent maintaining the system represents a cost since he/she is unable to perform other potentially important duties.

Material availability. Are the materials necessary to construct the chosen design available, either through local vendors or on the farmer's property as scrap? A significant number of materials in a biodigestion system are necessary for its constant operation, so in the event of a part failure the operator must be able to quickly replace it. For example, if the farmer owns property with many trees and has access to the proper labor, he/she can save on material costs by using wood from those trees to construct the protective structure around the reactor. If a farm has a given number of laborers that perform tasks around the property at a constant salary, the added cost of maintaining the system may be less noticeable. 


\subsection{Farm Characteristics}

Details specific to the property on which the biodigestion system is being considered may influence the profitability of the project.

Relative Locations of Waste Source and Cooking Location. It is necessary to transport gas through pipes or hosing from the reactor to the cooking area of the home. If these are far apart, the cost of the hose will increase. It is preferable that the cooking location be higher than that of the reactor since biogas naturally rises. If the cooking location is below the reactor, it may be necessary to design a system where gas is initially stored in a large portable plastic bag which can be moved to and from the two locations. Finally, if there are no fences, trees, or other structures over which the gas line can be hung, it may be necessary to install posts in order to do so, which would increase material and labor cost.

Need to protect reactor. The presence of animals, both large and small, as well as birds and bats (all of which are generally ubiquitous in developing nations), can threaten the long-term durability of the reactor, especially if it is made of plastic. If animals pose a danger to the reactor, a sturdy and well-built protective structure must be constructed, which will significantly raise the cost of the system. However, failure to do so could doom the project to an early demise, raising costs even further.

\subsection{Usage of System Benefits}

When calculating the profit from the system, the ideal metric is not necessarily how much gas or fertilizer is produced but how much is actually utilized.

Biogas utilization. In the case of a system that produces more gas than is used, the value of the gas produced cannot be used to calculate the profit from the system; rather, the best way to measure this would be in terms of a) cost savings from no longer purchasing cooking fuel, or b) where the gas is replacing wood-fire cooking, the economic benefits of the free time not spent gathering wood and the economic and/or environmental benefits of no longer using such a large quantity of firewood. If a family is not currently incurring a significant financial or environmental cost with their current method of cooking, a biodigestion system may not be a worthwhile endeavor.

Another important factor to consider here is the cost of cooking fuel and projections of its cost in the future. If cooking fuel (or the size of the family) is set to increase, the attractiveness of a biodigestion project also increases.

Fertilizer. If the effluent liquid is used either as a direct fertilizer or as a fertilizer for plants to be composted, any measurable gains in crop production or cost savings from no longer purchasing fertilizer can be included in a measurement of the economic benefit of a biodigestion system. However, if the effluent is not sufficiently utilized or goes to waste that potential profit opportunity is lost.

\subsection{Reactor Design}

Although there are many options in the design of a biodigestion system, they are not all 
necessarily dictated by any of the aforementioned factors. The shape, size, and material used for the system reactor have major implications on the economics of a biodigestion system.

Reactor Shape and Material Choice. There are a myriad of options for the shape and material used for the actual process of anaerobic digestion. In the developing world, large plastic bags, concrete pits with plastic tops, tanks, and even 55-gallon drums are common reactors. The chosen reactor design will have important ramifications on the initial cost, amount of maintenance necessary, and expected life. In situations where less capital is available, a cheaper, yet less durable option may be more attractive, whereas a farmer with access to credit may find a more expensive yet sturdier structure that requires less maintenance more feasible.

Reactor Size. Although the size of the reactor will generally be decided upon based on the amount of waste being produced, if a farmer plans on expanding the farm or wishes to use a large reactor essentially as a large gas storage unit as well, he or she may decide to build a larger reactor. Reactors with structural elements, such as concrete, will generally cost more per cubic meter than those consisting of plastic bags.

\subsection{Odor Reduction}

It is unlikely that the odor reduction from funneling animal waste through the reactor will result in any direct financial benefits, but in the rare event the farm benefits from this by becoming able to engage in other business activities, avoiding fines, or making some of its own land available for sale or lease, that can be included as a potential benefit of the system.

\section{Results and Discussion}

\subsection{Costa Rica Case Study}

In this section, the factors described in the previous sections are applied in order to analyze two biodigestion projects in rural Costa Rica.

Costa Rica is a small nation located within Central America. Unlike many of its neighbors, Costa Rica has enjoyed several decades of a stable, peaceful government and the steady expansion of social programs that can be credited with providing a higher quality of life compared to other nations at its income level. Although much of Costa Rica's population lives in urban areas and tourism has recently exceeded agriculture as the nation's most important industry, farming remains an important part of the country's economy and culture, and remains the focus of multiple government agencies (CIA World Factbook, 2013).

Table 1 provides a comparison of the two systems that were analyzed for this study. The first biodigestion system in this case study, System A (Figure 4), is part of a small farm on the sprawling property of a hotel located in a rural area alongside a road that links major tourist centers. This system provides for all of the cooking fuel necessary to run the hotel's restaurant at enormous cost savings. The hotel owner opted for a lower initial cost design that requires about 8 man-hours of maintenance per month. However, hotel maintenance staff whose duty it is to perform odd jobs around the property is available to perform maintenance, so the additional cost is more or less negligible. 


\section{Macrothink}

System B (Figure 5) was constructed on the property of a Costa Rican family living in a medium-sized rural community with technical assistance from the country's Ministry of Agriculture and Livestock (MAG). The system serves the cooking needs of a single family, and the father, who works the farm, performs the system maintenance.

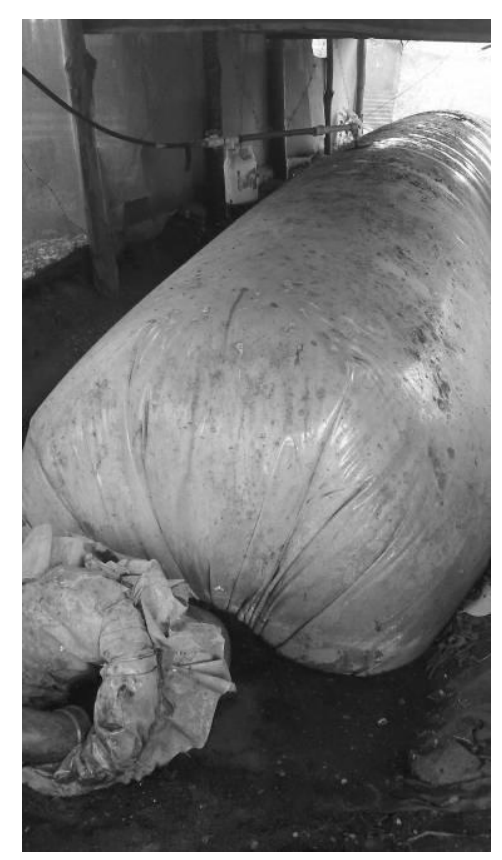

Figure 4. Biodigester System A - Salchicha

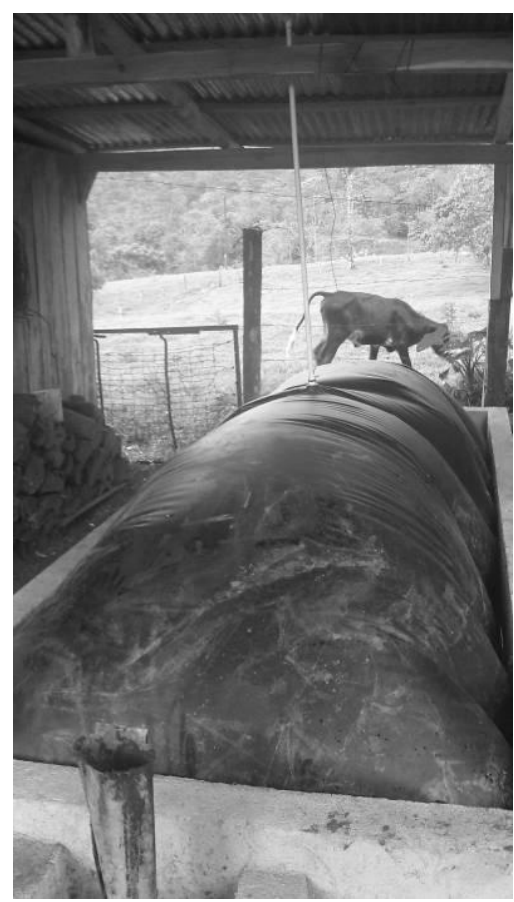

Figure 5. Biodigester System B - Media Salchicha 
Table 1. Properties of Biodigestion Systems A and B

\begin{tabular}{|l|l|l|}
\hline Category & Biodigestion System A & Biodigestion System B \\
\hline Design & Salchicha - "Sausage" & Media Salchicha - "Half-Sausage" \\
\hline $\begin{array}{l}\text { Property } \\
\text { Type }\end{array}$ & Pig Farm Located on Hotel Property & $\begin{array}{l}\text { Cow and Pig Farm Located on Small } \\
\text { Property with Home in Rural Comm. }\end{array}$ \\
\hline $\begin{array}{l}\text { Waste } \\
\text { Source }\end{array}$ & About 20 pigs & About 5 pigs, several chickens \\
\hline $\begin{array}{l}\text { Labor } \\
\text { Source }\end{array}$ & $\begin{array}{l}\text { Performed by Hotel Maintenance Staff, } \\
\text { \$20/day; always available }\end{array}$ & Performed by landowner \\
\hline $\begin{array}{l}\text { Material } \\
\text { Sourcing }\end{array}$ & $\begin{array}{l}\text { Hardware store nearby; large amounts of } \\
\text { scrap material on property; trees as wood } \\
\text { source }\end{array}$ & $\begin{array}{l}\text { Hardware store accessible by public bus, } \\
\text { some scrap material }\end{array}$ \\
\hline $\begin{array}{l}\text { Gas } \\
\text { Transport }\end{array}$ & $\begin{array}{l}\text { Cooking far from reactor, but higher } \\
\text { elevation and trees and fence available for } \\
\text { line }\end{array}$ & $\begin{array}{l}\text { Home 10m from digester, same elevation; } \\
\text { line strung above yard }\end{array}$ \\
\hline $\begin{array}{l}\text { Protective } \\
\text { Structure }\end{array}$ & $\begin{array}{l}\text { Many animals around; structure built } \\
\text { from scrap, fully protects reactor }\end{array}$ & $\begin{array}{l}\text { Utilizes existing structure; not protected } \\
\text { from animals }\end{array}$ \\
\hline
\end{tabular}

The two systems are similar but not identical in design, and many other factors influence their respective economic benefits. The characteristics of the biodigestion systems are summarized in Table 1.

The reactor design of System A, known as salchicha or "sausage," is nothing more than a large, long, double-layered plastic bag into which the water/pig manure mixture is placed. System B is a media salchicha, or "half-sausage," design, which consists of a deep concrete pit with hooks near the top that keep the top plastic sheet, which is attached to a PVC frame, at a constant level as it floats in the liquid mixture. The media salchicha requires a higher initial cost but usually lasts longer and its plastic top is easier to replace.

\subsection{Economic Benefit Analysis}

Table 2 displays the Net Present Value (NPV) analysis of biodigester A and B. Table 2 displays the initial material and labor costs, annual maintenance cost, annual gas production, and the resultant NPV of each system over a 20 year timeframe at a discount rate of $16 \%$ and an inflation rate of $5 \%$. A discount rate of $16 \%$ was used in these calculations as this is the borrowing interest rate for consumers in this area of Costa Rica (World Bank, 2013). System A has an expected life of 4 years and system B has an expected system life of 10 years. The NPV was calculated over a 20 year timeframe to compensate for the difference in system life between the systems and assumes replacement at the end of the useful life for 
each system. This will allow the systems to analyzed over an equal timeframe of 20 years with system A being replaced five time and system B being replaced 2 times. Tables 3 and 4 display the cash flow analysis over the 20 year time frame for biodigesters A and B respectively.

Table 2. NPV Analysis of Biodigester A and B

\begin{tabular}{|l|r|r|}
\hline Component & \multicolumn{1}{|c|}{ A } & \multicolumn{1}{|c|}{ B } \\
\hline Initial Material Cost $(\$)$ & -275 & -475 \\
\hline Initial Labor Cost (\$) & -240 & -150 \\
\hline Annual Maintenance Cost (\$) & -200 & -50 \\
\hline Annual Methane Generation Benefit (\$) & 850 & 250 \\
\hline Expected Life (years) & 4 & 10 \\
\hline NPV (20 year at 16\% discount rate in \$) & 4819 & 1156 \\
\hline Initial Cost & -515 & -625 \\
\hline Annual Benefit & 650 & 200 \\
\hline Simple Payback Period (Years) & 0.79 & 3.13 \\
\hline
\end{tabular}

Table 3. Cash Flow Analysis of Biodigester A

\begin{tabular}{|c|c|c|c|c|c|c|c|c|c|}
\hline Year & \multicolumn{2}{|c|}{ Material } & \multirow{2}{*}{$\begin{array}{l}\text { Labor } \\
\$(240.00)\end{array}$} & \multicolumn{2}{|c|}{ Maint } & \multicolumn{2}{|c|}{ Gas Prod. } & \multicolumn{2}{|c|}{ Total } \\
\hline 0 & $\$$ & $(275.00)$ & & $\$$ & $(200.00)$ & $\$$ & 850.00 & $\$$ & 135.00 \\
\hline 1 & & & & $\$$ & $(210.00)$ & $\$$ & 892.50 & $\$$ & 682.50 \\
\hline 2 & & & & $\$$ & $(220.50)$ & $\$$ & 937.13 & $\$$ & 716.63 \\
\hline 3 & & & & $\$$ & (231.53) & $\$$ & 983.98 & $\$$ & 752.46 \\
\hline 4 & $\$$ & (145.86) & $\$(291.72)$ & $\$$ & $(243.10)$ & $\$$ & $1,033.18$ & $\$$ & 352.50 \\
\hline 5 & & & & $\$$ & $(255.26)$ & $\$$ & $1,084.84$ & $\$$ & 829.58 \\
\hline 6 & & & & $\$$ & (268.02) & $\$$ & $1,139.08$ & $\$$ & 871.06 \\
\hline 7 & & & & $\$$ & $(281.42)$ & $\$$ & $1,196.04$ & $\$$ & 914.62 \\
\hline 8 & $\$$ & (177.29) & $\$(354.59)$ & $\$$ & (295.49) & $\$$ & $1,255.84$ & $\$$ & 428.46 \\
\hline 9 & & & & $\$$ & (310.27) & $\$$ & $1,318.63$ & $\$$ & $1,008.36$ \\
\hline 10 & & & & $\$$ & (325.78) & $\$$ & $1,384.56$ & $\$$ & $1,058.78$ \\
\hline 11 & & & & $\$$ & (342.07) & $\$$ & $1,453.79$ & $\$$ & $1,111.72$ \\
\hline 12 & $\$$ & $(215.50)$ & $\$(431.01)$ & $\$$ & (359.17) & $\$$ & $1,526.48$ & $\$$ & 520.80 \\
\hline 13 & & & & $\$$ & (377.13) & $\$$ & $1,602.80$ & $\$$ & $1,225.67$ \\
\hline 14 & & & & $\$$ & (395.99) & $\$$ & $1,682.94$ & $\$$ & $1,286.96$ \\
\hline 15 & & & & $\$$ & (415.79) & $\$$ & $1,767.09$ & $\$$ & $1,351.30$ \\
\hline 16 & $\$$ & (261.94) & $\$(523.89)$ & $\$$ & (436.57) & $\$$ & $1,855.44$ & $\$$ & 633.03 \\
\hline 17 & & & & $\$$ & $(458.40)$ & $\$$ & $1,948.22$ & $\$$ & $1,489.81$ \\
\hline 18 & & & & $\$$ & (481.32) & $\$$ & $2,045.63$ & $\$$ & $1,564.30$ \\
\hline 19 & & & & $\$$ & (505.39) & $\$$ & $2,147.91$ & $\$$ & $1,642.52$ \\
\hline $\mathrm{P} / \mathrm{F}$ & $\$$ & $(470.31)$ & $\$(630.63)$ & & $(1,821.54)$ & $\$$ & $7,741.53$ & $\$$ & $4,819.05$ \\
\hline
\end{tabular}


Table 4. Cash Flow Analysis of Biodigester B

\begin{tabular}{|c|c|c|c|c|c|c|c|c|c|}
\hline Year & & aterial & Labor & & Maint & & Gas Prod & & Total \\
\hline 0 & $\$$ & $(475.00)$ & $\$(150.00)$ & $\$$ & $(50.00)$ & $\$$ & 250.00 & $\$$ & $(425.00)$ \\
\hline 1 & & & & $\$$ & (52.50) & $\$$ & 262.50 & $\$$ & 210.00 \\
\hline 2 & & & & $\$$ & (55.13) & $\$$ & 275.63 & $\$$ & 220.50 \\
\hline 3 & & & & $\$$ & $(57.88)$ & $\$$ & 289.41 & $\$$ & 231.53 \\
\hline 4 & & & & $\$$ & $(60.78)$ & $\$$ & 303.88 & $\$$ & 243.10 \\
\hline 5 & & & & $\$$ & $(63.81)$ & $\$$ & 319.07 & $\$$ & 255.26 \\
\hline 6 & & & & $\$$ & $(67.00)$ & $\$$ & 335.02 & $\$$ & 268.02 \\
\hline 7 & & & & $\$$ & (70.36) & $\$$ & 351.78 & $\$$ & 281.42 \\
\hline 8 & & & & $\$$ & $(73.87)$ & $\$$ & 369.36 & $\$$ & 295.49 \\
\hline 9 & & & & $\$$ & (77.57) & $\$$ & 387.83 & $\$$ & 310.27 \\
\hline 10 & $\$$ & (97.73) & $\$ \quad(81.44)$ & $\$$ & (81.44) & $\$$ & 407.22 & $\$$ & 146.60 \\
\hline 11 & & & & $\$$ & (85.52) & $\$$ & 427.58 & $\$$ & 342.07 \\
\hline 12 & & & & $\$$ & (89.79) & $\$$ & 448.96 & $\$$ & 359.17 \\
\hline 13 & & & & $\$$ & (94.28) & $\$$ & 471.41 & $\$$ & 377.13 \\
\hline 14 & & & & $\$$ & (99.00) & $\$$ & 494.98 & $\$$ & 395.99 \\
\hline 15 & & & & $\$$ & (103.95) & $\$$ & 519.73 & $\$$ & 415.79 \\
\hline 16 & & & & $\$$ & $(109.14)$ & $\$$ & 545.72 & $\$$ & 436.57 \\
\hline 17 & & & & $\$$ & (114.60) & $\$$ & 573.00 & $\$$ & 458.40 \\
\hline 18 & & & & $\$$ & (120.33) & $\$$ & 601.65 & $\$$ & 481.32 \\
\hline 19 & & & & $\$$ & $(126.35)$ & $\$$ & 631.74 & $\$$ & 505.39 \\
\hline P/F & $\$$ & (497.15) & $\$(168.46)$ & $\$$ & (455.38) & $\$$ & $2,276.92$ & $\$$ & 1,155.92 \\
\hline
\end{tabular}

For system A, initial material cost - which includes burner, hose, bag, piping and fittings - is estimated at $\$ 275$, whereas the replacement material cost (which occurs every four years) is $\$ 120$, since only the bag needs to be replaced. This present $\$ 120$ cost rises at $5 \%$ inflation. For system B, initial material cost is $\$ 475$. Since the concrete pit is assumed to have at least a 20 -year life, the only replacement is assumed to be the plastic top at 10 years. The present cost is $\$ 60$ and rises at 5\% inflation. The 'Labor Cost' only refers to labor related to system replacement not to maintenance.

For system A, initial labor cost is high because there is more digging required. For replacement every four years, the lower amount of labor needed due to the ditch already being dug is offset by the task of taking out the entire reactor and setting up a new one. So labor is the same cost every four years, but rising at $5 \%$ annual inflation. For system B, initial labor cost is a bit lower due to less necessary digging and comes from the MAG pamphlet, but skilled labor may be required to construct the concrete pit. The replacement labor consists of making a new plastic frame, cutting the plastic sheet and placing it in the reactor. This is valued at a present cost of $\$ 50$, rising at $5 \%$ inflation.

The particular design of system A requires much more maintenance, consisting of mostly the labor of ensuring proper flow, filtering the waste and removing condensate water from the gas line. Its present value is $\$ 200$ per year and rises at $5 \%$ inflation. 
System B requires much less maintenance because the gas line is shorter and the concrete pit keeps the flow of waste more constant. The present value cost - mostly an opportunity cost, since the farmer would be working on other tasks if he/she were not maintaining the biodigestion system - of the maintenance is assumed to be $\$ 50$ and rises with 5\% inflation.

The gas production benefit of System A is simply the amount the owner used to spend on cooking gas prior to installing the system. Assuming usage and production stay current, the benefit of the system rises with 5\% inflation. The present gas production benefit of System B is calculated by making a ratio of the meals made at the hotel daily versus those made at the home daily. This gives it a present value of $\$ 250$ and is assumed to rise with $5 \%$ inflation. The bottom row gives the sum of the present values for each category. Due to the high lending rate of $16 \%$, the present value of costs and benefits that occur after year 10 are quite low.

The initial material and labor costs of System A were estimated from a personal communication with the hotel owner, while those of System B were calculated based on a pamphlet distributed by MAG, the Costa Rican government agency that assists rural farmers with the construction of biodigestion systems. The annual maintenance cost accounted for materials and labor; in the case of the farmer, the labor aspect of maintenance is an opportunity cost. Finally, the methane gas production for System A was easily calculated as the amount of gas the hotel spent on cooking fuel annually prior to installing the system, information provided by the hotel owner. The cost of the methane gas production for System B was extrapolated from the number calculated for A; instead of serving approximately 80 meals per day, this system was supporting approximately 20. Additionally, the ratio of animals to daily meals at each property was similar.

The specific circumstances of System A resulted in a higher net present value at the start of the project than those for System B. This is due to several of the factors discussed in the previous section. First and foremost, System A is not the only project in which the hotel is engaged, and as a result there is significant scrap material availability which helped drive down the initial cost. Most importantly, the gas usage at the hotel is likely a high percentage of that being produced, whereas the family with System B may not have been using as large a component of its produced gas, much of it escaping through the pressure relief valve.

Regarding the expected life of each reactor, the full plastic system (salchicha) employed by the hotel tends to more quickly develop sludge, a thick layer of waste, along the bottom of the reactor resulting in a shorter life; at this point the entire system must be replaced, whereas system B with a concrete pit and plastic top has much greater longevity and less required labor in order to change out the plastic if necessary.

\subsection{Discussion}

Regardless of which system design is used, both systems generate a positive economic return for the farmers/ investors and each are reasonable options for their respective situations. System A displayed a positive NPV $\$ 4,819$ and payback period of 0.79 year. System B displayed a positive NPV of $\$ 1,156$ and payback period of 3.13 years. Given the labor source and availability of scrap material at the hotel, the design for System A is an attractive option 
both in terms of NPV, initial cost, and payback period. When it requires significant monthly maintenance and gives out after four or five years, there are several trained employees ready to replace it. For an independent farmer that performs his or her own labor, the idea of having to replace a system every few years or perform monthly maintenance is not attractive when there are many other tasks to be performed. The media salchicha design requires much less upkeep. Finally, if the farmer using System B expands his/her farm, he may be able to sell excess gas to his neighbor at a discount, resulting in further economic benefits for both parties.

Finally, the intangible benefits of both systems must be mentioned. Although they were not calculated here, both parties used the effluent as a fertilizer: at the hotel, it was used to grow water lilies which were then placed in a fountain in the hotel's garden; the small-town farmer used it as fertilizer for chicken feed. In addition, these systems cause significant odor reduction, making work more pleasant for the farmer and the hotel employees. With regard to the environment, the methane that would have entered the atmosphere regardless is now entering it instead of other fossil fuels.

\section{Conclusions}

As a result of various technical and economic factors, biodigestion systems can be an attractive option for farmers in the developing world. As indicated by this study, an average sized farm in rural Costa Rica would experience a positive economic benefit from the implementation of such a system (approximately $\$ 1,150$ to $\$ 4,800$ over the life of the system in terms of NPV). The system would also allow for consistent heating fuel and reduce the need for energy infrastructure at the public or private level. This conclusion is consistent with other studies.

\section{References}

Archibugia, D., \& Coco., A. (2004). New Indicator of Technological Capabilities for Developed and Developing Countries (ArCo). World Development, 32, 629-654

Appels, L., Lauwersa, J., Degrèvea, J., Helsenb, L., Lievensc, B., Willemsc, K., Van Impea, J., \& Dewila, R. (2011). Anaerobic digestion in global bio-energy production: Potential and research challenges. Renewable and Sustainable Energy Reviews, 15, 4295- 4301.

Bell, M., \& Pavitt, K. (1997). Technological accumulation and industrial growth: contrasts between developed and developing countries. In D. Archibugi \& J. Michie (Eds.), Technology, globalisation and economic performance, 83-137, Cambridge: Cambridge University Press.

Budzianowski, W. M. (2012). Sustainable biogas energy in Poland: Prospects and challenges. Renewable and Sustainable Energy Reviews, 16, 342- 349.

CIA World Factbook. (2013). Costa Rica. Available at: https://www.cia.gov/library/publications/the-world-factbook/geos/cs.html, retrieved Mar. 2013.

Demirel, B., \& Scherer, P. (2008). Production of methane from sugar beet silage without manure addition by a single-stage anaerobic digestion process. Biomass and Bioenergy, 32, 
203-209.

Fine, P., \& Hadas, E. (2012). Options to reduce greenhouse gas emissions during wastewater treatment for agricultural use. Science of the Total Environment, 416, 289-299.

Han, S. K., Kim, S. H., H. W., \& Shin, H. S. (2005). Pilot scale two-stage process: A combination of acidogenic hydrogenesis and methanogensis. Water Science Technology, 52, 131-138.

Kaparaju, P. L. N., \& Rintala, J. A. (2005). Farm-scale anaerobic co-digestion of potato and its industrial by-products with pig manure. Resour Conserv Recycl, 43, 175-188.

Ke, S. Z., Shi, Z., \& Fang, H. H. P. (2005). Application of two phase anaerobic degradation in industrial waste water treatment. Int. J. Environmental Pollution, 23, 65-80.

Lall, S. (2001). Competitiveness indices and developing countries: an economic evaluation of the global competitiveness report. World Development, 29, 1501-1525.

Mohareb, A., Warith, M., \& Diaz, R. (2008). Modeling greenhouse gas emissions for municipal solid waste management strategies in Ottawa, Ontario, Canada. Resources, Conservation and Recycling, 52, 1241-1251.

Muhle, S., Balsam, I., \& Cheeseman, C. R. (2010). Comparison of carbon emissions associated with municipal solid waste management in Germany and the UK. Resources, Conservation, and Recycling, 54, 793-801.

Park, C. (2008). Fundamentals of Engineering Economics. Prentice Hall, New York, NY.

Pimenteira, C. A. P., Pereira, A. S., Oliveria, L. B., Rosa, L. P., Reis, M. M., \& Henriques, R. M. (2004). Energy conservation and CO2 emission reductions due to recycling in Brazil. Waste Management, 24, 889-897.

Rodríguez, L., \& Preston, T. R. (2012). Recycling Livestock Wastes. Available at: http://www.fao.org/WAICENT/FAOINFO/AGRICULT/AGA/AGAP/FRG/Recycle/default.ht m, retrieved Nov. 2012.

Weiske, A., Vabitsch, A., Olesen, J.E., Schelde, K., Michel, J., \& Friedrich, R. (2006). Mitigation of greenhouse gas emissions in European conventional and organic dairy farming. Agric Ecosyst Environ, 112, 221-232.

World Bank Economic Indicator Database. Available at: http://data.worldbank.org/indicator/FR.INR.LEND/countries/1W-CR?display=default, retrieved Mar. 2013.

\section{Copyright Disclaimer}

Copyright reserved by the author(s).

This article is an open-access article distributed under the terms and conditions of the Creative Commons Attribution license (http://creativecommons.org/licenses/by/3.0/). 